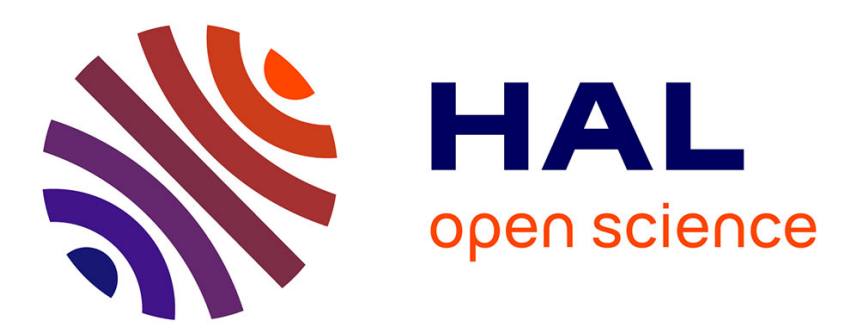

\title{
Challenging conservation of migratory species: Sahelian rainfalls drive first-year survival of the vulnerable Lesser Kestrel Falco naumanni
}

Jean-Baptiste Mihoub, Olivier Gimenez, Philippe Pilard, François Sarrazin

\section{To cite this version:}

Jean-Baptiste Mihoub, Olivier Gimenez, Philippe Pilard, François Sarrazin. Challenging conservation of migratory species: Sahelian rainfalls drive first-year survival of the vulnerable Lesser Kestrel Falco naumanni. Biological Conservation, 2010, 143 (4), pp.839 - 847. 10.1016/j.biocon.2009.12.026 . hal03516090

\author{
HAL Id: hal-03516090 \\ https://hal.science/hal-03516090
}

Submitted on 19 Jan 2022

HAL is a multi-disciplinary open access archive for the deposit and dissemination of scientific research documents, whether they are published or not. The documents may come from teaching and research institutions in France or abroad, or from public or private research centers.
L'archive ouverte pluridisciplinaire HAL, est destinée au dépôt et à la diffusion de documents scientifiques de niveau recherche, publiés ou non, émanant des établissements d'enseignement et de recherche français ou étrangers, des laboratoires publics ou privés. 


\title{
Challenging conservation of migratory species: Sahelian rainfalls drive first-year survival of the vulnerable Lesser Kestrel Falco naumanni
}

\author{
Jean-Baptiste Mihoub ${ }^{\mathrm{a}, *}$, Olivier Gimenez ${ }^{\mathrm{b}}$, Philippe Pilard ${ }^{\mathrm{c}}$, François Sarrazin ${ }^{\mathrm{a}}$ \\ a Université Pierre et Marie Curie, UMR 7204 MNHN-CNRS-UPMC “Conservation des Espèces, Restauration et Suivi des Populations”, CP 51, 61 rue Buffon, F-75005 Paris, France \\ ${ }^{\mathrm{b}}$ Centre d'Ecologie Fonctionnelle et Evolutive, Campus CNRS, UMR 5175, 1919 Route de Mende, F-34293 Montpellier Cedex 5, France \\ ${ }^{c}$ LPO Mission Rapaces, 26 Avenue Alain Guigue, F-13104 Mas-Thibert, France
}

\section{A R T I C L E I N F O}

\section{Article history:}

Received 4 March 2009

Received in revised form 16 December 2009

Accepted 26 December 2009

Available online $\mathrm{xxxx}$

\section{Keywords:}

Capture-recapture

Global changes

Raptor conservation

Wintering grounds

\begin{abstract}
A B S T R A C T
In the context of attested global changes, accurate estimation of whether climatic fluctuations impact on population demographic parameters is needed for adequate management, especially for migratory species. We present a capture-recapture analysis linking survival rates of the vulnerable Lesser Kestrel (Falco naumanni) to annual rainfalls in the Sahel region, considered as a proxy of climatic conditions on wintering grounds. Recapture data were obtained from field observations of individuals ringed and sexed as juveniles over a 14-year monitoring period (1994-2007). We addressed a common but problematic situation in birds where: (i) sex is known with certainty for first-summer or older birds but only suspected for juveniles, and (ii) a large proportion of individuals never return to the study population (e.g. transient behavior). Transient behavior and unknown sexes were explicitly integrated considering a two age class in a multistate capture-recapture model. Survival was time-varying for juveniles (geometric mean: $0.499 \pm 0.021)$ but constant - and higher - for adults $(0.718 \pm 0.013)$. Yearling survival probabilities were strongly correlated with rainfalls in the Sahel, suggesting a high dependence of juvenile upon the wintering conditions. While taking sex uncertainty into account, we detected no sex-dependence in survival. Incorporating the sensitivity of survival of wintering migratory birds to climatic variables such as precipitations in arid Sahelian ecosystem may allow to model conservation scenarios with a greater realism. Finally, we encourage the development of international management strategies for migratory species on wintering areas in addition to the existing conservation actions on summering Mediterranean grounds.
\end{abstract}

\section{Introduction}

Understanding and quantifying the forces driving the decline or the recovery of threatened species is the core of most conservation approaches. However, the definition of spatial and temporal scales of management may be challenging when the environmental processes impacting population dynamics occur at a large biogeographic level. This phenomenon is particularly strengthened for species that regularly migrate over long distances, and thus face a large range of biotic and abiotic conditions. Long-distance migratory species may therefore encounter damaged habitat or shifting conditions that could potentially act as threats. Among anthropogenic threats to biodiversity, the most famous is certainly global warming as a result of an increasing concentration of greenhouse gases (IPCC, 2007). Numerous studies identified correlations be-

* Corresponding author. Address: UMR 5173 MNHN-CNRS-UPMC, Conservation des Espèces, Restauration et Suivi des Populations, 61 rue Buffon, 75005 Paris, France. Tel.: +331407957 64; fax: +33140793835.

E-mail address: mihoub@mnhn.fr (J.-B. Mihoub). tween temperature increases or rainfall cycle changes and the phenology, the distribution or the demography of animal or plant species (e.g. Sæther et al., 2000; Forchhammer et al., 2001). Hence, since climatic conditions are known to strongly impact bird's population dynamics, notably the survival of wild populations (Newton, 1998), there is a crucial need to better assess the eventual effects of climate conditions on those demographic rates (Sæther et al., 2000; Grosbois et al., 2008).

We focused here on investigating the relations between climate fluctuations and survival of the Lesser Kestrel, Falco naummani, which has been classified vulnerable in the 2008 IUCN Red list (IUCN, 2008). The Lesser Kestrel is a colonial, long-distance migratory Palaearctic raptor, wintering in Africa, although a few populations now overwinter in Spain (Tella and Forero, 2000). Erstwhile widely distributed and among the most common raptors across Eurasia (Biber, 1990), this falcon suffered from a dramatic decline throughout its historical distribution range during the last decades (Hiraldo et al., 1996; Prugnolle et al., 2003). For instance, the Spanish population, representing $60-70 \%$ of the western European population, held ca. 100,000 breeding pairs in 1960 (Biljeveld, 1974) 
but was down to 12,000 pairs in 2000 (Atienza and Tella, 2004). Similar trends have been reported for other populations, e.g. in Israel (Liven-Schulman et al., 2004), and the species went almost extinct from numerous Mediterranean countries such as France at the beginning of the 1980's (Prugnolle et al., 2003). National extinctions have also been quoted in central Europe (Hiraldo et al., 1996). The species remains moreover of a primary conservation interest for the European Union and a European program Life Transfert for the protection of the Lesser Kestrel has been implemented since 2005.

Global changes, such as modification of land use practices (e.g. Donázar et al., 1993) or climate change (Rodriguez and Bustamante, 2003), have been incriminated for this collapse, but the exact causes of decline are still not well established (Forero et al., 1996; Franco et al., 2005). Studies aiming to explore factors of decline in this species were, to our knowledge, exclusively restricted to the breeding conditions in summering areas of the Mediterranean basin. However, there are at least three geographical components of major importance for the viability of migratory species, the summering area, the wintering area and transitory resting places. Surprisingly, no study has yet investigated the decline of the Lesser Kestrel linked to potential global changes impacting its African wintering conditions.

Lesser Kestrels of the Mediterranean basin usually winter in the Sahelian region (Pilard et al., 2004, 2005). Predators such as European long-distance migratory insectivorous raptors wintering in western Africa adjust their foraging behaviour to locust pulses (Sanchez-Zapata et al., 2007). Locusts and grasshoppers (Orthoptera: Acrididae ssp.) represent about $80 \%$ of Lesser Kestrels' diet in winter (from October to February; P. Pilard and C. Riols, unpublished data). On the other hand, the relative humidity and rainfalls are known to have a positive effect on the population dynamics of Acrididae (Kemp, 1992; Karpakakunjaram et al., 2002).

Climatic covariates of distinct seasonal critical periods (Brouwer et al., 2006; Grosbois et al., 2006) and distinct geographic locations (Schaub et al., 2005) may be particularly relevant for migratory population survival. According to the sensitivity of Lesser Kestrel population growth rate to survival rate (Hiraldo et al., 1996), and in a context of climate changes, we assessed the effect of annual rainfall - as a proxy of the general climatic fluctuations on the wintering grounds - on Lesser Kestrel survival. We also investigated the effect of sex and age. Indeed, age specific (Loery et al., 1987; Angelier et al., 2007) or sex-specific survival has been reported in bird species (e.g. Tavecchia et al., 2002; Badyaev et al., 2006), as a result of asymmetric investments during the breeding activity (Tavecchia et al., 2001) or energetic requirements (Torres and Drummond, 1997). Finally, we compared our results with those previously obtained in other European populations of the species and we discussed the implications of our results in providing recommendations for conservation priorities.

\section{Methods}

\subsection{Study species}

The Lesser Kestrel is a small colonial falcon inhabiting western Palaearctic agricultural plains, farmlands and urban areas mainly feeding on insects and on small vertebrates. Adult plumage shows a strong sexual dimorphism, so that sex assignation is straightforward (Negro et al., 1997). About $40-50 \%$ of birds surviving their first-year usually attempt to breed (Aparicio et al., 2007). In France, as in other Mediterranean countries, Lesser Kestrels are back from wintering grounds from March to breed, and leave in September (Aparicio and Bonal, 2002; Prugnolle et al., 2003). The wintering non-breeding area of Lesser Kestrels covers most of the African continent, from the Sahel region to South Africa. However, the majority of Lesser Kestrel from the Mediterranean basin likely winter in the western part of the Sahelian region. Communal roosts gathering several hundred to several thousand Lesser Kestrels have been recorded from western Senegal to Mali, Burkina Faso and South-eastern Niger (Pilard et al., 2004, 2005; P. Pilard, unpublished data). In 2009, a Lesser Kestrel originated from La Crau, one from Italy and three others from Spain have been identified in Senegal (Pilard, unpublished data), strengthening the hypothesis that western European Lesser Kestrels mainly wintered in western Sahel. Additionally, genetic analysis (Pepler et al., 1994) and ring recoveries (Oatley et al., 1998) indicated that Lesser Kestrels wintering in southern Africa were mostly from Eastern Europe or Asian countries.

\subsection{Study area and monitoring}

The monitoring study area was located in the steppe of the Plaine de Crau $\left(43^{\circ} 30^{\prime} \mathrm{N}, 4^{\circ} 50^{\prime} \mathrm{E}\right)$, East of the Rhône delta, Southern France. The population has been growing from two pairs in 1983 (the last breeding pairs for France) to 150 in 2009. Most of the breeding pairs were located in a restricted area of $10 \mathrm{~km}^{2}$, in several patchy nesting sites. Sheepfold ruins, artificial nest boxes under barn roofs and hollows of ground stone stacks offer suitable nest cavities. Monitoring was conducted during the breeding season (from March to August, about 20 weeks). The resighting periods were short relatively to the time interval between two resighting sessions, which is crucial in capture-recapture analyses (Nichols, 1992). A systematic monitoring has been achieved every year at the beginning of the breeding season in the Plaine de Crau to detect occupied colony. Colonies were surveyed at least twice a week. Fledglings were ringed at nest with a white DARVIC ring with a three-letters code on a tarsus, allowing later identification at distance. We used a total of 1421 individuals born in the study area and observations between 1994 and 2007. An individual was considered as resighted if it was seen at least once at the study site, at least one year after being ringed.

Sex of individuals was determined through plumage pattern observations of chicks during ringing sessions (Tella et al., 1996). However, birds may not have completely developed secondary sexual traits on plumage in very early live, misleading sex assignation. Many bird species show age- or sex-dependent dispersal and survival patterns, sometimes leading part of the population to exhibit fugitive presence, also called transient behaviour (Lebreton, 1995). Handling with potential bias related to sex and age in survival with standard capture-recapture models is problematic when sex uncertainty remains for individuals that are never resighted. In such cases, the transience and the level at which it occurs - e.g. age or sex - must be accounted for to avoid biased estimates (Pradel et al., 1997). Facing comparable worries as in Conroy et al. (1999), in Nichols et al. (2004) and in Pradel et al. (2008), we used a similar approach to explicitly integrate: (i) uncertainty about sex for young birds and (ii) transient behaviour for a sample of the population to estimate survival rates.

\subsection{Statistical methods}

\subsubsection{General model structure and notation}

To estimate parameters while handling with uncertainty in fledgling sexing, we used the Arnason-Schwarz model (Schwarz, 1993). Actually, accounting for any sex effect on survival when sex assignation is misleading would be impossible to achieve with a standard Cormack-Jolly-Seber, single state capture-recapture model. Within single state models, gender is considered as a fixed group for each individual, and does not allow individuals to move from a "wrong" sex assignation to its "correct" sex. This lack of 
flexibility is an issue when almost a third of the juveniles are never resighted, because the error rate in sex prediction cannot be considered for those birds and might bias parameter estimates. In contrast, multistate models enable individuals to move between different states through a matrix of transition probabilities, and allow dealing with uncertain sex determination from juvenile states to adult states for which sex was determined with $100 \%$ reliability. This flexible model structure allowed us using the whole monitoring data set in a global analysis, authorizing fully parameterized variation of age, time and sex in survival and resighting probabilities. Parameter estimation was carried out in the framework of the maximum likelihood theory (Lebreton et al., 1992) using program M-SURGE (Choquet et al., 2004).

In birds, survival has been reported to be age specific (Loery et al., 1987) and natal dispersal higher than breeding dispersal (Paradis et al., 1998). Therefore the first annual survival should be lower in juveniles than in adults, and the transient behaviour should affect juveniles. We defined three juvenile states and two adult states (Table 1 ) in order to estimate survival, resighting and transition probabilities ( $S, P$ and $\Psi$, respectively) (see Lebreton et al., 1992; Brownie et al., 1993). We tested for effects of time $(t)$, sex $(s)$ and two age classes (a2) on parameters $S$ and $P$ (Table $2)$. Time effect was considered as interacting $\left({ }^{*} t\right)$ or as additive $(+t)$ with sex and age.

\subsubsection{Model selection}

We used the Akaike information criterion (AIC $=-2 \log$ (likelihood) $+2 \times$ np, np being the number of estimable parameters) for model selection procedures. The AIC points to the most parsimonious model fitting the best the data with no more parameters than justified (Burnham et al., 1995; Conroy et al., 1999). The smaller the AIC value, the better the model is supported by the data. We used the threshold $\triangle \mathrm{AIC}$ score $\geqslant 2$ to distinguish between two models (Burnham and Anderson, 2002). As the goodness-of-fit test indicated significance for transience (see below), we used a modified version of the AIC, the quasi-AIC (QAIC; White and Burnham, 1999). The QAIC is the AIC adjusted by the variance inflation factor $\hat{c}\left(\hat{c}=\chi^{2} / \mathrm{df}\right)$, with $\mathrm{QAIC}=$ deviance $/ \hat{c}+2 \times \mathrm{np}$. The use of this empirical variance inflation factor remains a conservative strategy, limiting the risk of falsely rejecting the null hypothesis that the model fits the data (Lebreton et al., 2003).

\subsubsection{Goodness-of-fit}

We performed goodness-of-fit Test 2.CT and Test 3.SR for the single state model by using program U-CARE (Choquet et al., in press). Both tests have to be non-significant under the time-dependent Cormack-Jolly-Seber model to meet the homogeneity assumption (Lebreton et al., 1992). The two goodness-of-fit test components are sensitive to different sources of heterogeneity.

Table 1

State coding and transition parameter matrix. An uncertain sex was allocated to nestlings after hatching and true sex was identified on adults.

\begin{tabular}{|c|c|c|c|c|c|c|c|}
\hline \multirow[t]{2}{*}{ Status } & & & \multicolumn{5}{|c|}{ Transition parameter $(\Psi)$ matrix } \\
\hline & & & \multicolumn{3}{|c|}{ Yearling state } & \multicolumn{2}{|c|}{ Adult state } \\
\hline \multirow[t]{2}{*}{ Sex } & Class & State number & & & & & \\
\hline & & $\begin{array}{l}\text { To } \\
\text { From }\end{array}$ & 1 & 2 & 3 & 4 & 5 \\
\hline Unknown & Yearling state & 1 & 0 & 0 & 0 & $\Psi^{1,4}$ & $\Psi^{1,5}$ \\
\hline Male $^{*}$ & & 2 & 0 & 0 & 0 & $\Psi^{2,4}$ & $\Psi^{2,5}$ \\
\hline Female $^{*}$ & & 3 & 0 & 0 & 0 & $\Psi^{3,4}$ & $\Psi^{3,5}$ \\
\hline Male & Adult state & 4 & 0 & 0 & 0 & 1 & 0 \\
\hline Female & & 5 & 0 & 0 & 0 & 0 & 1 \\
\hline
\end{tabular}

Uncertain predicted sex allocation.

Table 2

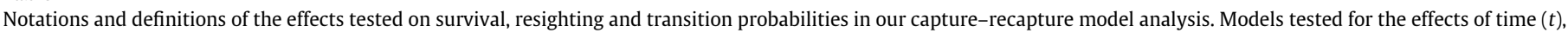
sex $(s)$ and age between yearling and adult $(a)$. Effects with interaction are written with $a\left({ }^{*}\right)$ and additive effects with $a(+)$.

\begin{tabular}{|c|c|c|c|c|c|}
\hline \multirow[t]{2}{*}{ Notation } & \multicolumn{2}{|c|}{ Sex effect } & \multicolumn{2}{|c|}{ Time effect } & \multirow[t]{2}{*}{ Definition } \\
\hline & Yearling & Adult & Yearling & Adult & \\
\hline$a 2$ & & & & & No sex and no time effect on the two age classes \\
\hline$a 2^{*} s$ & $\times$ & $\times$ & & & Sex effect on the two age classes \\
\hline$a(1)^{*} s / a(2)$ & $\times$ & & & & Sex effect on yearlings only \\
\hline$a(1) / a(2)^{*} s$ & & $\times$ & & & Sex effect on adults only \\
\hline$a 2+t$ & & & $\times$ & $\times$ & Additive time effect on the two age classes \\
\hline$a 2^{*} t$ & & & $\times$ & $\times$ & Time effect on the two age classes \\
\hline$a(1)^{*} t / a(2)$ & & & $\times$ & & Time effect on yearlings only \\
\hline$a(1) / a(2)^{*} t$ & & & & $\times$ & Time effect on adults only \\
\hline$a(1)^{*} t / a(2)^{*} s$ & & $\times$ & $\times$ & & Time effect on yearlings, sex effect on adults \\
\hline$a(1)^{*} s / a(2)^{*} t$ & $\times$ & & & $\times$ & Time effect on adults, sex effect on yearlings \\
\hline$a 2^{*} s+t$ & $\times$ & $\times$ & $\times$ & $\times$ & Sex and additive time effect on the two age classes \\
\hline$a 2^{*} s^{*} t$ & $x$ & $\times$ & $\times$ & $\times$ & Sex and time effect on the two age classes \\
\hline$a(1)^{*} s^{*} t / a(2)$ & $\times$ & & $\times$ & & Sex and time effect on yearlings only \\
\hline$a(1) / a(2)^{*} s^{*} t$ & & $\times$ & & $\times$ & Sex and time effect on adults only \\
\hline$a(1)^{*} s^{*} t / a(2)^{*} s$ & $\times$ & $\times$ & $\times$ & & Sex effect on the two age classes, time effect on yearlings only \\
\hline$a(1)^{*} s / a(2)^{*} s^{*} t$ & $\times$ & $\times$ & & $\times$ & Sex effect on the two age classes, time effect on adults age class only \\
\hline$\left[a(1)^{*} s / a(2)\right]+t$ & $\times$ & & $\times$ & $\times$ & Additive time effect on the two age classes, sex effect on yearlings only \\
\hline$\left[a(1) / a(2)^{*} s\right]+t$ & & $\times$ & $\times$ & $\times$ & Additive time effect on the two age classes, sex effect on adults only \\
\hline$\left[a(1)^{*} s / a(2)\right]^{*} t$ & $\times$ & & $\times$ & $\times$ & Time effect on the two age classes, sex effect on yearlings only \\
\hline$[a(1) / a(2) s]^{*} t$ & & $\times$ & $\times$ & $\times$ & Time effect on the two age classes, sex effect on adults only \\
\hline
\end{tabular}


Test 3.SR aims at detecting transience effect, while Test 2.CT tests for a trap-dependence effect. Heterogeneity in survival and resighting probabilities among individuals can bias parameter estimates, e.g. when transience occurs (Pradel et al., 1997; Prévot-Julliard et al., 1998). If the data met the assumptions of single state model, the multistate model should fit the data well (Brown et al., 2003).

\subsection{Biological hypothesis}

To test a parsimonious number of hypotheses on age, sex, time and rainfall effects, we performed our analysis through a two step selection procedure (Grosbois et al., 2008). In a first step, we crossed a reduced number of hypotheses to narrow the set of candidate models according to prior biological knowledge (Burnham and Anderson, 2002). In the second step, we tested whether precipitation in the wintering area influenced survival using the best models provided by the first selection step. Mean survival resulted from geometric mean and standard error (SE) were obtained through the delta-method (Seber, 1982).

\subsubsection{First step: reducing the number of hypotheses}

Since some transitions could not be observed, we fixed parameters with unrealizable attributes (Clobert et al., 1994). An individual is juvenile only in the first-year of life and we then fixed the transition parameters from a juvenile to any juvenile state at 0 , as well as transition from adult to juvenile states (Table 1). We also fixed transitions from an adult sex state to itself to 1, assuming no error in sex determination for adults. In addition, we assumed no effect of time on transition probabilities. With respect to resighting probabilities, we considered no sex effect for both yearlings and adults since: (i) chicks were caught randomly at nests, (ii) resightings of adults were mainly made on paired breeders. The reduced set of hypotheses in the first selection step resulted in 20 hypotheses on survival, five hypotheses on resighting and one hypothesis on transition probabilities.

\subsubsection{Second step: assessing the effect of Sahel rainfall on survival}

The assignation of external covariates of potential biological interest is a common way to pertinently narrow the number of parameters of time-dependent models (Grosbois et al., 2008). The potential effect of the rainfalls in the wintering area (RS in parameter notation) is likely to drive the abundance of preys and can explain time variation in survival. We applied the rainfall covariates on time-dependent models according to the first step selection. Rainfall effects were tested on the survival only. There was actually no reason to believe that resighting probabilities on French colonies or transitions from the predicted sex to the true sex could depend on rainfalls in Africa. Many studies resorted to large scale climate proxies to study temporal variations of demographic parameter, mainly because the influence of climatic factors at local scale can be weak (see Stenseth et al., 2002). In addition, it is very likely that Lesser Kestrel from the Mediterranean basin wintered in the western Sahel, from western Senegal to south-eastern Niger (Pilard et al., 2004, 2005; P. Pilard, unpublished data). Lesser Kestrels from all the western European populations gathered in premigratory roosting places in France, Spain or Italy before travelling to Africa, mixing together birds of different countries. Hence, there was no reason to believe that birds from La Crau wintered in a particular resting place different from those of other western European birds. Instead, French birds may be distributed across the numerous roosting places spread over the large extent of the wintering area in the Sahel region. In this context, the use of a large scale measurement of the climatic covariates appeared conservative. Sahelian rainfall covariates were precipitation data extracted from the Climate Prediction Center Merged Analysis Precipitation (CMAP) database (www.cdc.noaa.gov/cdc/data.cmap.html) of the western Sahelian region $10-20 \mathrm{~N}, 20 \mathrm{~W}-10 \mathrm{E}$, during the period 1994-2006. Precipitation data arose from merging rain gauges observations with estimates from infrared and microwave satellite data (Xie and Arkin, 1997), and we calculated the mean daily standardized annual rainfalls.

An alternative approach would be using integrative covariates, such as vegetation index (e.g. Normalized Difference Vegetation Index (NDVI), see Schaub et al., 2005; Svoray et al., 2008; Grande et al., 2009), to relate demographic parameters to environmental variation. Therefore, we also performed early modeling procedures considering the NDVI variables obtained from the Africa Data Dissemination Service website (http://igskmncnwb015.cr.usgs.gov/ adds) within the same spatial area as considered for rainfall data. These previous modeling procedures demonstrated no effect of NDVI on Lesser Kestrel survival. Thus, despite the generally strong correlation between vegetation and climatic variables, the vegetation index could not fully reveal all factors affecting land surface functioning in Sahel (Philippon et al., 2005). Even though vegetation may inform on food availability for phytophagous insects (Schaub et al., 2005), vegetation obviously did not integrate all factors relevant for locust abundance in relation to rainfalls, e.g. humidity needed for egg-emergences (Karpakakunjaram et al., 2002).

\subsubsection{Testing the impact of rainfall on survival}

Significance of the relationship between Sahel rainfalls and survival were assessed through an analysis of deviance (Anodev; Skalski, 1996). Under the null hypothesis that rainfall has not significant effect, the Anodev follows a Fisher-Snedecor distribution with 1 and $\left(n p_{t}-n p_{\text {cov }}\right)$ degrees of freedom, $n p_{t}$ and $n p_{\text {cov }}$ being the number of parameters in the time-dependent model and the model with covariates, respectively. The Anodev compares deviances of the constant survival model $\left(D e v_{c t}\right)$, of the time-dependent model $\left(\operatorname{Dev}_{t}\right)$ and of the model with covariates $\left(\operatorname{Dev}_{c o v}\right)$ :

$F_{- \text {Anodev }}=\frac{D e v_{c t}-D e v_{c o v}}{D e v_{c o v}-D e v_{t}} \times\left(\mathrm{np}_{\mathrm{t}}-\mathrm{np}_{\text {cov }}\right)$

When the Anodev showed a significant trend between survival and the covariates, we evaluated the fraction of variation in survival accounted by the covariates (Grosbois et al., 2008) using the following statistics (Skalski, 1996):

$\mathrm{R}^{2} \operatorname{Dev}=\frac{\operatorname{Dev} v_{c t}-\operatorname{De} v_{c o v}}{\operatorname{Dev} v_{c t}-\operatorname{De} v_{t}}$

$R^{2}$ Dev can be seen as a squared correlation coefficient and provides a robust estimate of the minimum fraction of the temporal variation in survival accounted for by the covariates (Grosbois et al., 2008). All tests were performed with the version 2.5.1 of the R statistical software (Ihaka and Gentleman, 1996).

\section{Results}

\subsection{Goodness-of-fit}

Goodness-of-fit test indicated a significant lack of fit $\left(\chi_{35}^{2}=\right.$ $239.502, P<0.001)$. When examining the two goodness-of-fit components separately, Test 2.CT showed no significant trap-dependent effect $\left(\chi_{11}^{2}=16.8509, P=0.112\right)$. The transient test Test 3.SR was significant $\left(\chi^{2}{ }_{12}=189.919, P<0.001\right)$, indicating that a large proportion of marked birds were never seen again. Such violation of the Cormack-Jolly-Seber model assumptions requires using an alternative capture-recapture model structure accounting for heterogeneity (Pradel et al., 1997). Accordingly, we considered a two age class structure on survival to accommodate for this transient effect. The goodness-of-fit test for this model, based on the re- 
moval of component Test 3.SR from the overall goodness-of-fit, was still significant $\left(\chi_{23}^{2}=49.483, P<0.001\right)$. To handle with this residual heterogeneity, we adjusted the AIC scores in QAIC scores in the model selection procedure by a variance inflation factor $\hat{c}=2.151$.

\subsection{Model selection and parameter estimates}

The model selection procedure favoured a model with agedependence of survival: a first age class of yearling, exhibiting transient behaviour, and a second age class being adults. The general model $\left[S_{a 2 * s * t}, P_{a 2 * t}, \Psi_{a(1) * *}\right]$ tested for an interaction of sex and time effects on the two age class survival probabilities, for an interaction of time effect on the two age classes on resighting probabilities, and for a sex effect on transition from juvenile states to adult states.

\subsubsection{First step model selection}

The ten best ranked models of the first step model selection (Table 3) supported the hypothesis that resighting probabilities varied with time and age additively. According to these results, resighting probabilities were higher for adults (from $0.715 \pm 0.118$ in 1998 to $0.988 \pm 0.012$ in 2003) than for yearlings (from $0.311 \pm 0.136$ in 1998 to $0.947 \pm 0.053$ in 2003 ), with similar yearly variations (Fig. 1).

Biological inferences on survival probabilities were however more contentious (Table 3 ). The five first models were within $\triangle$ QAIC $<2$, suggesting contrasting hypotheses on survival trends. At this stage, uncertainty remained to formalise conclusions about the way in which survival rates were affected, from the constancy of the parameter to a sex effect or a time effect or both. Therefore, explaining time variations through the use of external covariates in over-parameterized time-dependent models should provide more conclusive results by increasing statistical power.

\subsubsection{Second selection step}

Considering the additive time-dependent model $S_{a 2+t}$, survival variations across time appeared to be better explained when adding the Sahelian rainfall as external covariate than by the single time effect $\left(\triangle \mathrm{QAIC}=5.7084\right.$ between model $S_{a 2+t * \mathrm{RS}}$ and model $S_{a 2+t}$; Tables 3 and 4 ). The rainfall dependent survival hypothesis was favoured in contrast to the hypothesis of constant survival $\left(\triangle \mathrm{QAIC}=5.3789\right.$ between model $S_{a 2+t * \mathrm{RS}}$ and model $\left.S_{a 2}\right)$ and Sahel rainfalls explained significantly more than $31 \%$ of the deviance in temporal variation of survival probabilities (Anodev 1, Table 5). Besides, the other inference testing was more conspicuous when considering the external Sahelian covariates (Table 4). For instance, the sex effect inference was clearly rejected whatever the age class $\left(\triangle \mathrm{QAIC}=4.4496\right.$ with the model $S_{[a(1) / a(2) * s]+t * \mathrm{RS}}$; rank 3, Table 4). Additionally, AIC model selection suggested that only yearling survival could be actually affected by annual Sahel rainfalls, whereas adult survival could stay constant $(\triangle \mathrm{QAIC}=2.8584$ between the best model $S_{a(1) * t * \mathrm{RS} / a(2)}$ and the model $S_{a 2+t * \mathrm{RS}}$; rank 2, Table 4 ). Conclusively, Anodev statistics confirmed that only yearling survival was dependent on Sahel rainfalls, which explained $46 \%$ of the deviance in yearling survival $\left(R^{2} \operatorname{Dev}=0.463\right.$; Anodev 2 , Table $5)$. Temporal variations of yearling survival were presented in Fig. 2. Adult survival, was constant $(0.718 \pm 0.013)$, and yearling survival varied from $0.263 \pm 0.041$ (interval 2002-2003) to $0.599 \pm 0.036$ (interval 2003-2004), with mean $0.499 \pm 0.021$.

Lastly, transition probabilities between chicks sex allocation and the adult sex (model $\left.S_{a(1) * t * \mathrm{RS} / a(2)}\right)$ revealed a reliable sex assignation from presumed male to adult male $\left(\Psi^{2,4}=0.9828 \pm 0.0128\right)$. However, sex allocation for females was less efficient, with about

Table 3

QAIC scores of the ten best models obtained during the first model selection step (i.e. without the Sahelian rainfall covariates).

\begin{tabular}{|c|c|c|c|c|c|c|}
\hline Rank & Model & & Number of parameters & Deviance & QAIC & $\triangle \mathrm{QAIC}$ \\
\hline 1 & $S_{a 2}$ & $P_{a 2}+t$ & 19 & 4427.4877 & 2096.3392 & - \\
\hline 2 & $S_{a 2+t}$ & $P_{a 2+t}$ & 31 & 4376.5724 & 2096.6687 & 0.3295 \\
\hline 3 & $S_{a(1) / a(2) * s}$ & $P_{a 2+t}$ & 20 & 4426.6963 & 2097.9713 & 1.6321 \\
\hline 4 & $S_{[a(1) / a(2) * s]+t}$ & $P_{a 2+t}$ & 32 & 4375.3258 & 2098.0892 & 1.75 \\
\hline 5 & $S_{a(1) * t / a(2)}$ & $P_{a 2+t}$ & 31 & 4379.9285 & 2098.2289 & 1.8897 \\
\hline 6 & $S_{[a(1) * s / a(2)]+t}$ & $P_{a 2+t}$ & 32 & 4376.4844 & 2098.6278 & 2.2886 \\
\hline 7 & $S_{a(1) * t / a(2) * s}$ & $P_{a 2+t}$ & 32 & 4379.1584 & 2099.871 & 3.5318 \\
\hline 8 & $S_{a 2 * s+t}$ & $P_{a 2+t}$ & 33 & 4375.2646 & 2100.0607 & 3.7215 \\
\hline 9 & $S_{a(1) * S * t / a(2)}$ & $P_{a 2+t}$ & 32 & 4379.8529 & 2100.1938 & 3.8546 \\
\hline 10 & $S_{a(1) * S * t / a(2) * s}$ & $P_{a 2+t}$ & 33 & 4379.1023 & 2101.8449 & 5.5057 \\
\hline
\end{tabular}

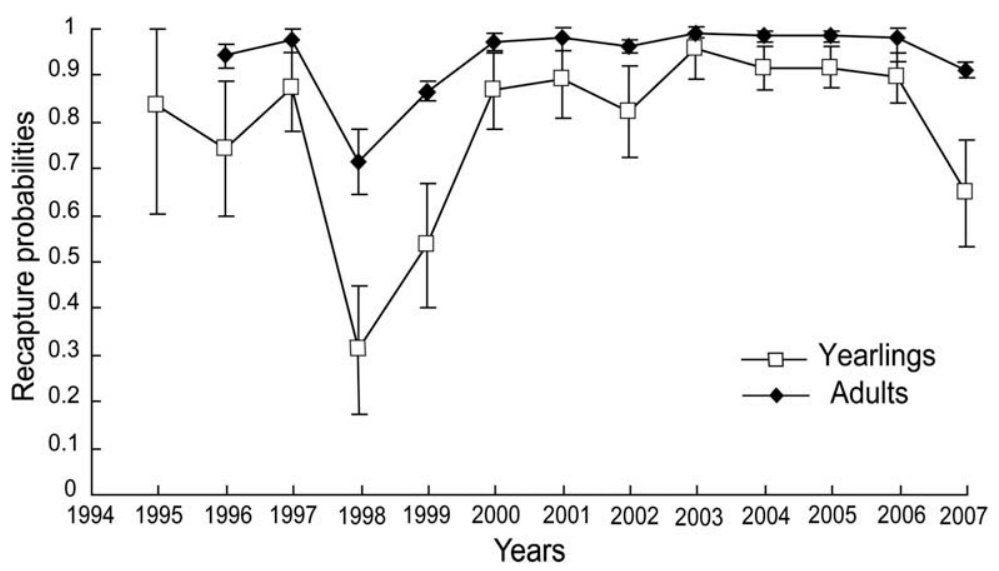

Fig. 1. Additive time-dependent resighting probabilities of the Lesser Kestrel population at La Plaine de Crau, France. 
Table 4

QAIC scores of the five best models obtained during the second model selection step (with the Sahelian rainfall covariates).

\begin{tabular}{|c|c|c|c|c|c|c|}
\hline Rank & Model & & Number of Parameters & Deviance & QAIC & $\triangle \mathrm{QAIC}$ \\
\hline 1 & $S_{a(1) * t * \mathrm{RS} / a(2)}$ & $P_{a 2+t}$ & 20 & 4405.4671 & 2088.1019 & - \\
\hline 2 & $S_{a 2}+t * \mathrm{RS}$ & $P_{a 2+t}$ & 20 & 4411.6155 & 2090.9603 & 2.8584 \\
\hline 3 & $S_{[a(1) / a(2) * S]+t * \mathrm{RS}}$ & $P_{a 2+t}$ & 21 & 4410.7364 & 2092.5515 & 4.4496 \\
\hline 4 & $S_{a 2}$ & $P_{a 2+t}$ & 19 & 4427.4877 & 2096.3392 & 8.2372 \\
\hline 5 & $S_{a(1) / a(2) * s}$ & $P_{a 2+t}$ & 20 & 4426.6963 & 2097.9713 & 9.8694 \\
\hline
\end{tabular}

Table 5

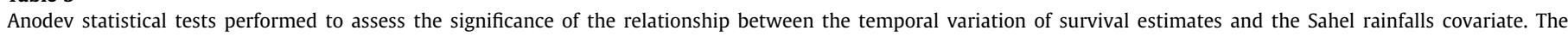

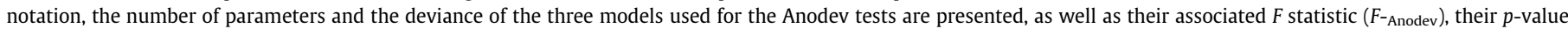
significance level $(P$-Anodev $)$ and their squared correlation coefficient $\left(R^{2} D e v\right)$ accounting for the fraction the Sahel rainfalls covariate on temporal survival variations.

\begin{tabular}{|c|c|c|c|c|c|c|}
\hline Models & & Number of parameters & Deviance & $F$-Anodev & $P$-Anodev & $R^{2}$ Dev \\
\hline \multicolumn{7}{|l|}{ Anodev 1} \\
\hline$S_{a 2}$ & $P_{a 2+t}$ & $\mathrm{np}_{\mathrm{ct}}=19$ & $D e v_{c t}=4427.4877$ & 4.9823 & 0.0473 & 0.312 \\
\hline$S_{\mathrm{a} 2+t}$ & $P_{a 2+t}$ & $n p_{t}=31$ & $D e v_{t}=4376.5724$ & & & \\
\hline$S_{a 2}+t * \mathrm{RS}$ & $P_{a 2+t}$ & $n p_{\text {cov }}=20$ & $D e v_{c o v}=4411.6155$ & & & \\
\hline \multicolumn{7}{|l|}{ Anodev 2} \\
\hline$S_{a 2}$ & $P_{a 2+t}$ & $\mathrm{np}_{\mathrm{ct}}=19$ & $D e v_{c t}=4427.4877$ & 9.4847 & 0.0105 & 0.463 \\
\hline$S_{a(1) * / a(2)}$ & $P_{a 2+t}$ & $\mathrm{np}_{\mathrm{t}}=31$ & $D e v_{t}=4379.9285$ & & & \\
\hline$S_{a(1) * t * \mathrm{RS} / a(2)}$ & $P_{a 2+t}$ & $n p_{\text {cov }}=20$ & $D e v_{c o v}=4405.4671$ & & & \\
\hline
\end{tabular}

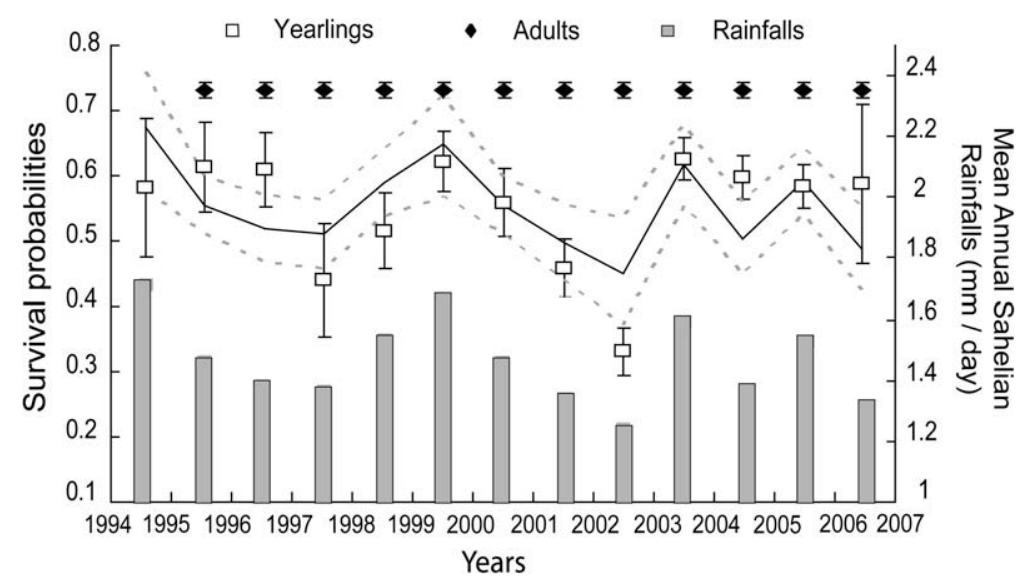

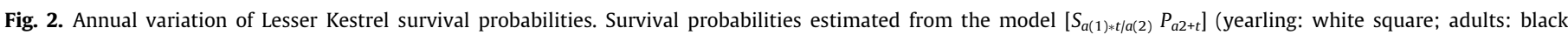

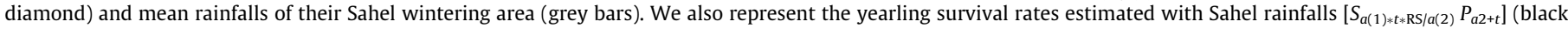
line) and their 95\% confidence interval (dashed grey line).

$11 \%$ of chicks sexed as females being actually adult males $\left(\Psi^{3,4}=\right.$ $0.1144 \pm 0.0295$ ). Considering unknown sexed chicks resighted at least once as adult, about half were males. Additionally, transition probabilities remained very similar for all models given in Tables 3 and 4 , suggesting robust estimates of transition parameters.

\section{Discussion}

\subsection{Resighting and transition probabilities}

Resightings of yearlings and adults were affected in the same way (Fig. 1), in line with previous conclusions for this population (Prugnolle et al., 2003). Yearlings exhibited lower resighting rates, suggesting that they were more difficult to observe than older individuals. Actually, Lesser Kestrels are sexually mature at the end of the first-year of life, but can also stay non-breeders. Yearlings remaining non-breeder may be more prone to vagrancy, making them less easy to see than adults.

Transition probabilities suggested that the sex-ratio of birds for which sex was unknown as chicks and returning to La Crau was close to 1 , slightly biased toward males $\left(\Psi^{1,4}=0.5263 \pm 0.1367\right)$. False female assignations were more frequent than false male assignations $\left(\Psi^{3,4}=0.1144 \pm 0.0295 ; \quad \Psi^{2,5}=0.0172 \pm 0.0128\right)$. In fact, males sexed as chicks may not fully exhibit their sexual plumage determinants, and may look like a young female. It was impossible to estimate the chick sex-ratio or to infer either sexdependence in the transient behaviour. Actually, the true sex was only known for birds that survived and did not disperse to another place, so that transition probabilities were estimated from birds that were resighted at the study area.

\subsection{Survival estimates}

Survival was strongly and positively correlated with annual rainfall of the Sahelian wintering area. Sahel rainfalls appeared to affect only yearlings, adult survival being constant over time (Fig. 2). In contrast, the effect of sex on survival was not detected, while we could suspect e.g. asymmetric costs between sexes due to the energetically costly egg-laying period (Tavecchia et al., 2001), nest predation during the brooding (Serrano et al., 2004) or size 
differences between sexes (Torres and Drummond, 1997). Mortalities at the breeding site appeared to be of low incidence compared to the mortality during the overall year, confirming previous conclusions that sex-dependence of Lesser Kestrel survival was unlikely (Serrano et al., 2005).

Survival was quite high for adults $(0.718 \pm 0.013)$, and varied between $0.263 \pm 0.041$ and $0.599 \pm 0.036$ for yearlings (mean $0.499 \pm 0.021$ ). The fact that young were more sensitive to Sahelian rainfalls than adults could entail two main explanations. First, juveniles and adults could winter on different areas across the western Sahel. However, according to field observations, resting places gathered young as well as adults in the same places (P. Pilard, unpublished data), so that in absence of more robust information this hypothesis is not very much supported. Second, the difference between young and adults could reside in hunting skills, adults having higher competing abilities and experiences than young. Lesser Kestrel survival of the La Crau population was close to that obtained in a previous study of the same population (Prugnolle et al. (2003); $0.67 \pm 0.06$ and $0.57 \pm 0.05$ for adult and juvenile, respectively) and was in accordance with other European populations (e.g. in adults $0.72 \pm 0.015$ in large colonies in Serrano et al. (2005) and 0.7101 in Hiraldo et al. (1996)). Prugnolle et al. (2003) underlined that the difference between yearling survival in La Crau and Spanish populations approached significance, according to yearling survival of 0.34 in Hiraldo et al. (1996). Local survival estimates did not explicitly disentangle breeding or natal dispersal from mortality. Low survival may be explained both by dispersal into other populations for juvenile that survived but emigrated, as well as by juveniles that died during the first-year of life. Hiraldo et al. (1996) warned against a possible underestimation of yearling survival due to a strong natal dispersal. The French population of La Crau is quite isolated from others, whereas Spain supports a dense network of Lesser Kestrel populations. Accordingly, Spanish populations may exchange more individuals with others than the La Crau population, and since fidelity increases with age (Serrano et al., 2001), non philopatric birds will definitely disappear from their initial colony while still alive.

Lastly, the strong impact of Sahel rainfalls on juvenile survival could be generalized to all western European breeding populations. Until recently, little was known about wintering areas of European Lesser Kestrel but the identification of French, Italian and Spanish Lesser Kestrels in Senegal corroborate the hypothesis of common resting areas in winter for birds of the western Europe (P. Pilard, unpublished data). Annual survival of Lesser Kestrel may likely be driven both locally on breeding grounds (e.g. local climatic conditions, nest predation) and globally on wintering grounds (e.g. by Sahel rainfalls).

\subsection{Effect of environmental conditions on survival and causes of decline}

The western European populations of Lesser Kestrel have experienced rapid declines, equivalent to $46 \%$ in each decade since 1950 (Biber, 1990). Several hypotheses have been proposed to explain this decline, basically falling into two types of factors: those affecting reproduction and those affecting survival. The reduction of suitable nest site availability and the related increasing competition with other cavity nester species (Blanco and Tella, 1997; Franco et al., 2005), as well as the increasing use of pesticides reducing egg fertility (Bustamante, 1997), seemed to decrease fecundity. Climate changes and spring precipitations have been shown to impact breeding success (Rodriguez and Bustamante, 2003). Although accounting for a part of the slump of the species, reproduction should have been dramatically low to be entirely held responsible for the historical decline, since the population growth rate of Lesser Kestrel is more sensitive to survival than to fecundity (Hiraldo et al., 1996). The diminution of Lesser Kestrels populations was likely to mainly result from reduced survival, through predation and changes in foraging habitat structure or quality linked to modifications in land uses (Cramp and Simmons, 1980; Donázar et al., 1993). Surprisingly, to our knowledge, all the studies aiming to infer the decline of the Lesser Kestrels only focused on factors acting on the summering area, and none on wintering areas. Yet, shifts in foraging behaviour of long-distance migratory raptors species, resulting in an increase of their group size, coincide with locust eruptions in arid sub-Saharan area (Sanchez-Zapata et al., 2007), and reproductive success of European long-distance migratory insectivorous birds decreased with insect availability (Newton, 2004). Our results do not prove causal relationship between locust dynamics and Lesser Kestrel survival. Nevertheless, Lesser Kestrel survival related to Sahelian rainfalls may corroborate the central place of locust pulses in arid sub-Saharan food webs (Sanchez-Zapata et al., 2007). The rainiest period in the Sahel (from June to September) corresponds to the reproductive season of Orthopterans, happening just before the arrival of Lesser Kestrels. Survival may be largely and negatively affected by a reduction in the availability of the insect feeding resource. Severe drought episodes in the Sahel region occurred during the last decades (Shanahan et al., 2009). Past droughts have certainly contributed to reduce Lesser Kestrel survival, likely explaining a strong part of the historical decline of the species in strengthening the impact of threats acting in the Mediterranean area.

\subsection{Linking climate to demographic parameters}

Dealing with climatic variables is needed for evaluations of species sustainability, and may help to identify more precisely the spatial extent of wintering grounds in long-distance migratory birds. Indeed, in species for which information on non-breeding resting places remains limited, evidence for effects of local or regional variables on demographic parameters can corroborate hypotheses based on limited field observations. In addition, assessing the sensitivity of the growth rate and population viability in response to the predicted magnitude of global changes can improve the relevance of future conservation scenarios, including e.g. larger stochastic range of variation in demographic parameters. Besides, climatic variables, such as precipitation and temperature, can benefit from available predictions (IPCC, 2007), and can offer population dynamics forecasting (Jenouvrier et al., 2009).

\subsection{European migrant bird conservation in the Sahel}

Severe drought episodes causing substantial ecological disturbances will likely impact the Sahel in the future (Shanahan et al., 2009). Such predictions provide realistic scenarios and opportunities to point future conservation priorities. For instance, identifying switch in environmental changes may help defining the continental or regional scale at which efforts should focus for the conservation of migratory species. Even if not much can be done to counter the severity of droughts, the preservation of particular habitats of current or future distribution ranges from other threats could buffer effects of climate changes. A gathering of more than 28,000 Lesser Kestrels has been reported in a single resting place of 0.5 hectare and whose feeding area covered less than $8000 \mathrm{~km}^{2}$ in Senegal in 2007 (P. Pilard, unpublished data). This strong gregarious behavior, concentrating between $30 \%$ and $50 \%$ of the west European populations in such a "hotspot", may have huge implications for species conservation and entails maintaining the integrity of resting places and their surrounding areas.

The dependence of European long-distance migratory birds on Sahelian rainfall and on locust emergence could explain a significant part of the decline of Afro-Palaearctic migrant birds wintering 
in African open lands through the last 25 years. At the same time, many locust and grasshopper species remain agricultural pests in the Sahel region (Skaf et al., 1990). Strategies to control Acridid have been widely used during the last decades (Lomer et al., 2001), and can still represent a threat to migratory and resident bird species in sub-Saharan areas. Links between threatened species and plague species entail several problematic issues. Chemical pesticide sprayings narrowed Acrididae population abundance and range throughout Africa during the last decades (Duranton and Lecoq, 1990), and organochlorine contaminants may decrease both survival (Mineau, 2002) and fertility in birds (Bouwman et al., 2008). Pest controls aim to protect human livelihoods from their damages and remain obviously of an indisputable necessity. Locust controls have then to be carefully rationalized to maintain both human benefits and ecosystem conservation (Sanchez-Zapata et al., 2007). Conservation efforts at the Mediterranean basin only may be fruitless if nothing is done to protect African wintering grounds. Partnerships between human populations and governmental institutions must be encouraged to cooperate in order to coordinate conservation efforts at local and international scales.

\section{Acknowledgements}

The monitoring and the survey of the population began in 1983 by the LPO Mission Rapaces and the Conservatoire-Etudes des Ecosystèmes de Provence (CEEP). Financial supports were provided by the European Union through a "LIFE program", by the National restoration plan for Lesser Kestrel and by the French ministry of Research. We owe special thanks to P. Camberlain who provide the climatic data and to F. Jiguet for great advices and comments on an early version of this manuscript.

\section{References}

Angelier, F., Moe, B., Weimerskirch, H., Chastel, O., 2007. Age-specific reproductive success in a long-lived bird: do older parents resist stress better? Journal of Animal Ecology 76, 1181-1191.

Aparicio, J.M., Bonal, R., 2002. Effects of food supplementation and habitat selection on timing of Lesser Kestrel breeding. Ecology 83, 873-877.

Aparicio, J.M., Bonal, R., Munoz, A., 2007. Experimental test on public information use in the colonial Lesser Kestrel. Evolutionary Ecology 21, 783-800.

Atienza, J.C., Tella, J.L., 2004. Cernícalo primilla, Falco naumanni. In: Madroño, A., González, C., Atienza, J.C. (Eds.), Libro Rojo de las Aves de España. Dirección General para la Biodiversidad-SEO/BirdLife, Madrid, pp. 161-163.

Badyaev, A.V., Hamstra, T.L., Oh, K.P., Seaman, D.A.A., 2006. Sex-biased maternal effects reduce ectoparasite-induced mortality in a passerine bird. Proceedings of the National Academy of Sciences of the United States of America 103, 14406-14411.

Biber, J.P., 1990. Action Plan for the Conservation of Western Lesser Kestrel (Falco naumanni) Populations. ICBP, Cambridge.

Biljeveld, M., 1974. Birds of Prey in Europe. Macmillan, London.

Blanco, G., Tella, J.L., 1997. Protective association and breeding advantages of choughs nesting in lesser kestrel colonies. Animal Behaviour 54, 335-342.

Bouwman, H., Polder, A., Venter, B., Skaare, J.U., 2008. Organochlorine contaminants in cormorant, darter, egret, and ibis eggs from South Africa. Chemosphere 71, 227-241.

Brouwer, L., Richardson, D.S., Eikenaar, C., Komdeur, J., 2006. The role of group size and environmental factors on survival in a cooperatively breeding tropical passerine. Journal of Animal Ecology 75, 1321-1329.

Brown, C.R., Covas, R., Anderson, M.D., Bomberger-Brown, M., 2003. Multistate estimate of survival and movement in relation to colony size in the sociable weaver. Behavioral Ecology 14, 463-471.

Brownie, C., Hines, J.E., Nichols, J.D., Pollock, K.H., Hestbeck, J.B., 1993. Capturerecapture studies for multiple strata including non-Markovian transitions. Biometrics 49, 1173-1187.

Burnham, K.P., White, G.C., Anderson, D.R., 1995. Model selection in the analysis of capture-recapture data. Biometrics 51, 888-898.

Burnham, K.P., Anderson, D.R., 2002. Model Selection and Multimodel Inference. A Practical Information-Theoretic Approach, second ed. Springer-Verlag, New York (USA).

Bustamante, J., 1997. Predictive models for Lesser Kestrel Falco naumanni distribution, abundance and extinction in southern Spain. Biological Conservation $80,153-160$.

Choquet, R., Reboulet, A.-M., Pradel, R., Gimenez, O., Lebreton, J.-D., 2004. M-SURGE: new software specifically designed for multistate capture-recapture models. Animal Biodiversity and Conservation 27, 207-215.
Choquet, R., Lebreton, J.-D., Gimenez, O., Reboulet, A.-M., Pradel, R., in press. UCARE: utilities for performing goodness of fit tests and manipulating CAptureREcapture data. Ecography.

Clobert, J., Lebreton, J.-D., Allainé, D., Gaillard, J.M., 1994. The estimation of agespecific breeding probabilities from recaptures or resightings of marked animals. II Longitudinal models. Biometrics 50, 375-387.

Conroy, M.J., Senar, J.C., Hines, J.E., Domenech, J., 1999. Development and application of a mark-recapture model incorporating predicted sex and transitory behaviour. Bird Study 46, S62-S73.

Cramp, S., Simmons, K.E.L. (Eds.), 1980. Handbook of the Birds of the Western Palaearctic. Oxford Press, Oxford.

Donázar, J.A., Negro, J.J., Hiraldo, F., 1993. Foraging habitat selection, land-use changes and population decline in the lesser kestrel Falco naumanni. Journal of Applied Ecology 30, 512-522.

Duranton, J.F., Lecoq, M., 1990. Ecology of locusts and grasshoppers (Orthoptera, Acrididae) in Sudanese west Africa. I. Discriminant factors and ecological requirements of acridian species. Acta Oecologica 1, 151-164.

Forchhammer, M.C., Clutton-Brock, T.H., Lindström, J., Albon, S.D., 2001. Climate and population density induce long-term cohort variation in a northern ongulate. Journal of Animal Ecology.

Forero, M.G., Tella, J.L., Donázar, J.A., Hiraldo, F., 1996. Can interspecific competition and nest site availability explain the decrease of lesser kestrel Falco naumanni populations? Biological Conservation 78, 289-293.

Franco, A.M.A., Marques, J.T., Sutherland, W.J., 2005. Is nest-site availability limiting Lesser Kestrel populations? A multiple scale approach. Ibis 147, 657666.

Grande, J.M., Serrano, D., Tavecchia, G., Carrete, M., Ceballos, O., Diaz-Delgado, R., Tella, J.L., Donazar, J.A., 2009. Survival in a long-lived territorial migrant: effects of life-history traits and ecological conditions in wintering and breeding areas. Oikos 118, 580-590.

Grosbois, V., Henry, P.-Y., Blondel, J., Perret, P., Lebreton, J.-D., Thomas, D.W., Lambrechts, M.M., 2006. Climate impacts on Mediterranean blue tit survival: an investigation across seasons and spatial scales. Global Change Biology 12, 2235-2249.

Grosbois, V., Gimenez, O., Gaillard, J.M., Pradel, R., Barbraud, C., Clobert, J., Møller A.P., Weimerskirch, H., 2008. Assessing the impact of climate variation on survival in vertebrate populations. Biological Reviews (Cambridge) 83, 357399.

Hiraldo, F., Negro, J.J., Donazar, J.A., Gaona, P., 1996. A demographic model for a population of the endangered lesser kestrel in southern Spain. Journal of Applied Ecology 33, 1085-1093.

Ihaka, R., Gentleman, R., 1996. R: a language for data analysis and graphics. Journal of Computational and Graphical Statistics 5, 299-314.

IPCC, 2007. Fourth Assessment Report on Climate Change. Contribution of Working Groups of the Intergovernmental Panel of Climate Change, Cambridge University Press, Cambridge, UK.

IUCN, 2008. IUCN Red List of Threatened Species. IUCN, Gland, Switzerland.

Jenouvrier, S., Caswell, H., Barbraud, C., Holland, M., Stroeve, J., Weimerskirch, H., 2009. Demographic models and IPCC climate projections predict the decline of an emperor penguin population. Proceedings of the National Academy of Sciences of the United States of America 106, 1844-1847.

Karpakakunjaram, V., Kolatkar, M.D., Muralirangan, M.C., 2002. Effects of abiotic factors on the population of an acridid grasshopper, Diabolocatantops pinguis (Orthoptera: Acrididae) at two sites in southern India: a three-year study. Journal of Orthoptera Research 11, 55-62.

Kemp, W.P., 1992. Temporal variation in rangeland grasshopper (Orthoptera: Acrididae) communities in the steppe region of Montana, USA. Canadian Entomologist 124, 437-450.

Lebreton, J.-D., Burnham, K.P., Clobert, J., Anderson, D.R., 1992. Modeling survival and testing biological hypothesis using marked animals: a unified approach with case studies. Ecological Monographs 62, 67-118.

Lebreton, J.-D., 1995. The future of population dynamics studies using marked individuals: a statistician's perspective. Journal of Applied Statistics 22, 10091030.

Lebreton, J.-D., Hines, J.E., Pradel, R., Nichols, J.D., Spendelow, J.A., 2003. Estimation by capture-recapture of recruitment and dispersal over several sites. Oikos 101, 253-264.

Liven-Schulman, I., Leshem, Y., Alon, D., Yom-Tov, Y., 2004. Causes of population declines of the Lesser Kestrel Falco naumanni in Israel. Ibis 146, 145-152.

Loery, G., Pollock, K.H., Nichols, J.D., Hines, J.E., 1987. Age-specificity of avian survival rates: an analysis of capture-recapture data for a black-capped chickadee population. Ecology 68, 1038-1104.

Lomer, C.J., Bateman, R.P., Johnson, D.L., Langewald, J., Thomas, M., 2001. Biological control of locusts and grasshoppers. Annual Review of Entomology 46, 667702.

Mineau, P., 2002. Estimating the probability of bird mortality from pesticide sprays on the basis of the field study record. Environmental Toxicology and Chemistry 21, 1497-1506.

Negro, J.J., Hiraldo, F., Donázar, J.A., 1997. Causes of natal dispersal in the lesser kestrel: inbreeding avoidance or resource competition? Journal of Animal Ecology 66, 640-648.

Newton, I., 1998. Population Limitation in Birds. Academic Press, San Diego, USA London, UK.

Newton, I., 2004. Population limitation in migrants. Ibis 146, 197-226.

Nichols, J.D., 1992. Capture-recapture models using marked animals to study population dynamics. Bioscience 42, 94-102. 
Nichols, J.D., Kendall, W.L., Hines, J.E., Spendelow, J.A., 2004. Estimation of sexspecific survival from capture-recapture data when sex is not always known. Ecology (New York) 85, 3192-3201.

Oatley, T.B., Oschadleus, H.D., Navarro, R.A., Underhill, L.G., 1998. Review of Ring Recoveries of Birds of Prey in Southern Africa: 1948-1998. Endangered Wildlife Trust, Johannesburg, South Africa.

Paradis, E., Baille, S.R., Sutherland, W.J., Gregory, R.D., 1998. Patterns of natal and breeding dispersal in birds. Journal of Animal Ecology 67, 518-536.

Pepler, D., Martin, R., Fouché, F., van Hensbergen, B., 1994. Radionuclide analysis of Lesser Kestrels Falco naumanni and the origin of populations overwintering in southern Africa. Ostrich 65, 122-126.

Philippon, N., Mougin, E., Jarlan, L., Frison, P.L., 2005. Analysis of the linkages between rainfall and land surface conditions in the west African monsoon through CMAP, ERS-WSC, and NOAA-AVHRR data. Journal of Geophysical Research Atmospheres 110, 40-54.

Pilard, P., Thiollay, J.M., Rondeau, G., 2004. Données sur l'hivernage du faucon crécerellette Falco naumanni en Afrique de l'Ouest. Alauda 72, 323-328.

Pilard, P., Corveler, T., Roche, H.P., Girard, C., 2005. Données sur l'ivernage du faucon crécerellette Falco naumanni au Niger. Alauda 73, 137-140.

Pradel, R., Hines, J.E., Lebreton, J.-D., Nichols, J.D., 1997. Capture-recapture survival models taking account of transients. Biometrics 53, 60-72.

Pradel, R., Maurin-Bernier, L., Gimenez, O., Genovart, M., Choquet, R., Oro, D., 2008 Estimation of sex-specific survival with uncertainty in sex assessment. The Canadian Journal of Statistics 36, 29-42.

Prévot-Julliard, A.C., Lebreton, J.-D., Pradel, R., 1998. Re-evaluation of adult survival of black headed gulls (Larus ridibundus) in presence of recapture heterogeneity. Auk 115, 85-95.

Prugnolle, F., Pilard, P., Brun, L., Tavecchia, G., 2003. First-year and adult survival of the endangered Lesser Kestrel Falco naumanni in southern France. Bird Study 50, 68-72.

Rodriguez, C., Bustamante, J., 2003. The effect of weather on lesser kestrel breeding success: can climate change explain historical population declines? Journal of Animal Ecology 72, 793-810.

Sæther, B.-E., Tufto, J., Engen, S., Jerstad, K., Røstad, O.W., Skåtan, J.E., 2000 Population dynamical consequences of climate change for a small temperate songbird. Science 287, 854-856.

Sanchez-Zapata, J.A., Donazar, J.A., Delgado, A., Forero, M.G., Ceballos, O., Hiraldo, F. 2007. Desert locust outbreaks in the Sahel: resource competition, predation and ecological effects of pest control. Journal of Applied Ecology 44, 323-329.

Schaub, M., Kania, W., Köppen, U., 2005. Variation of primary production during winter induces synchrony in survival rates in migratory white storks Ciconia ciconia. Journal of Animal Ecology 74, 656-666.

Schwarz, C.J., 1993. Estimating migration rates using tag recovery data. In: Lebreton, J.-D., North, P.M. (Eds.), Marked Individuals in the Study of Bird Population. Birkhäuser Verlag, Basel, Switzerland, pp. 255-264.
Seber, G.A.F., 1982. The Estimation of Animal Abundance and Related Parameters, second ed. Charles Griffin and Co., London.

Serrano, D., Tella, J.L., Forero, M.G., Donazar, J.A., 2001. Factors affecting breeding dispersal in the facultatively colonial lesser kestrel: individual experience vs. conspecific cues. Journal of Animal Ecology 70, 568-578.

Serrano, D., Forero, M.G., Donazar, J.A., Tella, J.L., 2004. Dispersal and social attraction affect colony selection and dynamics of lesser kestrels. Ecology 85, 3438-3447.

Serrano, D., Oro, D., Ursúa, E., Tella, J.L., 2005. Colony size selection determines adult survival and dispersal preferences: allee effects in a colonial bird. American Naturalist 166, E22-E31.

Shanahan, T.M., Overpeck, J.T., Anchukaitis, K.J., Beck, J.W., Cole, J.E., Dettman, D.L., Peck, J.A., Scholz, C.A., King, J.W., 2009. Atlantic forcing of persistent drought in west Africa. Science 324, 377-380.

Skaf, R., Popov, G.B., Roffey, J., 1990. The Desert locust: an international challenge. Philosophical Transactions of the Royal Society of London B Biological Sciences 328, 525-538.

Skalski, J.R., 1996. Regression of abundance estimates from mark-recapture surveys against environmental covariates. Canadian Journal of Fisheries and Aquatic Sciences 53, 196-204.

Stenseth, N.C., Mysterud, A., Ottersen, G., Hurrell, J.W., Chan, K.-S., Lima, M., 2002. Ecological effects of climate fluctuations. Science 297, 1292-1296.

Svoray, T., Shafran-Nathana, R., Henkinb, Z., Perevolotsky, A., 2008. Spatially and temporally explicit modeling of conditions for primary production of annuals in dry environments. Ecological Modelling 218, 339-353.

Tavecchia, G., Pradel, R., Boy, V., Johnson, A.R., Cézilly, F., 2001. Sex- and age-related variation in survival and cost of first reproduction in Greater Flamingos. Ecology (New York) 82, 165-174.

Tavecchia, G., Pradel, R., Lebreton, J.-D., Biddau, L., Mingozzi, T., 2002. Sex-biased survival and breeding dispersal probability in a patch population of the Rock Sparrow Petronia petronia. Ibis 144, E79-E87.

Tella, J.L., DonÃzar, J.A., Negro, J.J., Hiraldo, F., 1996. Seasonal and interannual variations in the sex-ratio of lesser kestrels Falco naumanni. Ibis 138, 342345.

Tella, J.L., Forero, M.G., 2000. Farmland habitat selection of wintering lesser kestrels in a Spanish pseudosteppe: implications for conservation strategies. Biodiversity and Conservation 9, 433-441.

Torres, R., Drummond, H., 1997. Female-biased mortality in daughters of a bird with size dimorphism. Journal of Animal Ecology 66, 859-865.

White, G.C., Burnham, K.P., 1999. Program MARK: survival estimation from populations of marked animals. Bird Study 46, S120-S139.

Xie, P., Arkin, P., 1997. Global precipitation: a 17-year monthly analysis based on gauge observations, satellite estimates and numerical model outputs. Bulletin of the American Meteorological Society 78, 2539-2558. 